\title{
Genotype detection of fimH gene of Acinetobacter baumannii isolated from different clinical cases
}

\author{
Rana Mujahid Abdullah* \\ Rasha Zaid Tariq Ahmed \\ *Department of Biology/ College of Education Ibn-Al Haitham/ University of Baghdad \\ E-mail : dr.rana_alshwaikh@yahoo.com
}

\begin{abstract}
Background: Forty isolates were obtained of Acinetobacter baumannii from (200) samples, the samples were collected from different cases including: - wounds, burns, Stool, Urinary tract infection urine.

Aim of study: The aim of study is to isolate and diagnose Acinetobacter baumanniii from different clinical cases and to investigate the fim $H$ gene.

Objective: Respiratory tract infection and blood sample.For the period between 1/9/2016 to 30/11/2016.

Materials and methods: Identification of 40 isolates confirmed to be Acinetobacter baumannii included 9 isolates from blood, 1 isolate from urinary tract infections, 4 isolates from each of wound infections and Respiratory tract infection, 8 isolates from burns and 14 isolates from stool sample.

Results: The result revealed that the fimH gene was present in (20) isolates $(50 \%)$ of Acinetobacter baumannii. The result Showed (7) isolate (17.5\%) of Stool and blood has fimH gene to each of them and Burns (3) isolates $(7.5 \%)$ has fimH gene and (2) isolate $(5 \%)$ of respiratory tract infection has fimH gene and finally only (1) isolate $(2.5 \%)$ of Wound infection. While all isolated for each of the urinary tract infections doesn't the fimH gene. The gel electrophoresis showed that the molecular weight of fim $H$ gene was 508 bp.

Conclusion: Sequential analysis detection of fimH showed three silent mutations that did not affect the amino acid translation.
\end{abstract}

Key Words: Acinetobacter baumannii, fimH gene, PCR polymorphism.

\section{Introduction}

Acinetobacter species are Gram negative bacteria, Strict aerobic, catalase positive, oxidase negative, non-motile, but some species bacteria have a kind of movement Twitching Motility because of polarity fimbriae $(1,2)$.

These bacterial opportunistic pathogens are responsible for many opportunistic infections in the hospital including pneumonia, burns infection wound infection, septicemia, endocarditis and urinary tract infection $(3,4)$.

Many virulence factors have an effect on the risk and morbidity of these bacteria, including the age of the patient, length time of stay in the hospital, resistance to antibiotics, long treatment of broad-spectrum antibiotics and immunosuppressive drugs, as well as chronic diseases such as heart disease, diabetes and hypertension $(5,6)$.

Acinetobacter species include several types of A. baumannii species. These bacteria have many of the virulence factors that help them cause disease like capsule formation, production of biofilm and production of enzymes such as lipase, protease, Gelatinase activity, Pellicle assay, Siderphores, production of colic in, formation of polysaccharides, adhesion to living cells and non-living surfaces $(7,8)$.

Several studies have indicated that the fimA gene encodes the large secondary unit while the fim $F$ and fim $G$ genes encode the small subunits and the fim $H$ gene encodes the top of the cilia that are sensitive to the manus and the fim $C$ gene encodes the attached protein that helps the fim protein pass through the Periplasms and fimD encodes the outer membrane proteins and fimI encodes For the structural of the grass and molecular weight of fimH gene was $508 \mathrm{bp}(9,10)$. The fimH gene is an important virulence agent for bacteria. Which encodes the Type 1 fimbraie, that helps bacteria bind to the surface of host cells and then cause injury.

The aim of study is to isolate and diagnose A. baumanniii from different clinical cases and to investigate the fimH gene.

Materials and methods

1. Sample collection: 200 samples of different diseases were collected from (wounds, burns, stools, urinary tract infection, respiratory tract infections, bacteremia) from several hospitals in Baghdad, from several hospitals in the of Baghdad city (Central Children's Hospital, Al Karama Hospital, Karkh General Hospital, Al-Ameen Medical City Hospital, Educational Labs, Baghdad Teaching Hospital, Child Protection Hospital, Burns and Wounds Hospital). For the period from 1/9/2016 to 30/11/2016. Samples collection included 50 isolates from blood, 20 isolates from urinary tract 
infections, 30. isolates from wound infections, 40 isolates from burn infections , 35 isolate from Respiratory tract infection and 25 isolates from stool samples

2. Bacterial isolation and diagnosis: Samples were diagnosed using blood agar and MacConkey agar, and biochemical tests such as Catalase and Oxidase were used. For the final diagnosis of isolates, API 20E and Vitek 2 were used (11).

3. DNA extraction: A special kit (Promega, USA) was used to extract the Genomic DNA Purification Kit from bacterial isolates according to the instructions of the manufacturer Promega (USA).

4. Detection of the fimH gene: Prepare the primer solution for FimH F Forward and FimH R Reveries accordance the instructions of the manufacturer Alpha (DNA) using sterilized ionic distilled water to obtain a concentration of 100 picommol / microliter and present each solution of the initiates separately at 10 picomol / microliter by taking 10 microliters of the Stock Solution and add 90 microliters of distilled ionic distilled water and store the stock solutions under $-20^{\circ} \mathrm{C}$, mixing of the solution after removing it from the ice using vortex before use. GO Taq Green Master Mix PCR Promega (USA).

5. PCR reaction: Using PCR amplification conditions shown in Table (1).

Table (1): The initiator used in this study and the interactive conditions used in PCR reaction

\begin{tabular}{ccccc}
\hline Source & $\begin{array}{c}\text { Product } \\
\text { size }(\mathrm{bp})\end{array}$ & Primer sequence & primer \\
& $\mathbf{5} \longrightarrow$ ' $^{\prime}$ & & \\
\hline \multirow{2}{*}{ Johnson and Stell (2000) } & 508 & TGCAGAACGGATAAGCCGTGG & F & fimH \\
& & GCAGTCACCTGCCCTCCGGTA & R & \\
\hline
\end{tabular}

6. Detection of the fimH gene: The steps of replication to investigate the gene fimH (12). The program was modified as follows initial denaturation ( $94^{\circ}$ for 4 minutes), 34 cycles $\left(94^{\circ} \mathrm{C}\right.$ for 60 second $),\left(45\right.$ seconds at $\left.56^{\circ} \mathrm{C}\right)$ and $\left(60\right.$ seconds at $\left.72^{\circ} \mathrm{C}\right)$. The final step included $(10$ minutes and at $72^{\circ} \mathrm{C}$ for final elongation)

7. The reaction products were extracted using Bio-Basic INC (Canada) $(5 \mu \mathrm{l})$ of products with a concentration of (agarose gel) 2\% containing 5 microliters of Eithidium bromide Bio Basic INC (Canada) and using (5 $\mu \mathrm{l})$ of DNA ladder (100-1500) (Promega, USA) base pairs and 100 volts for 80 min. UV light Optima (Japan) (13).

8. Sequencing analysis of DNA sequencing: DNA samples fim $\mathrm{H}$ gene with $\mathrm{F}$ and $\mathrm{R}$ primer were sent to the Macrogen Inc. South Korea Geumchen, Seoul) The results of the BioEdit Sequence Alignment Editor Software (DNASTER, Madison, WI, USA) are available on the National Center for Biotechnology Information (NCBI) and protein translation by Clustar Omega to determine the number of nucleotides Mutations and their effect on protein translation.

\section{Result and discussion}

Acinetobacter baumannii is one of the most common types of bacteria that cause septicemia, followed by respiratory tract infections (NSA) and isolated from hospital-acquired pneumonia (pneumoconial infection) and persistent ambulatory peritoneal dialysis (CAPD) (14).

After identification for bacterial diagnosis and relying on (11) was obtained 40 isolates confirmed to be Acinetobacter baumannii included 14 isolates (35\%) from stool sample, 9 isolates $(22.5 \%)$ from blood, 8 isolates $(20 \%)$ from burns, 4 isolate $(10 \%)$ from each of wound infections and Respiratory tract infection and 1 isolate $(2.5 \%)$ from urinary tract infections Table (2).

Table (2): Source, number and percentages of Acinetobacter baumannii isolates

\begin{tabular}{rccc}
\hline No. & Source of A. baumannii & number & $\%$ \\
\hline 1 & Bacteremia (blood) & 9 & 22.5 \\
2 & Respiratory tract Infection & 4 & 10 \\
3 & Wounds & 4 & 10 \\
4 & Burns & 8 & 20 \\
5 & Stool & 14 & 35 \\
6 & UTI & 1 & 2.5 \\
& Total & 40 & 100 \\
\hline
\end{tabular}


A.baumanni, fimH genes were detected using a PCR. The results showed that A. baumannii isolates possessed these genes in different proportions. As shown in Table (3). The results showed that 19 isolates (47.5\%) of A. baumannii possessed the fimH gene. The resulting packets with a molecular weight were $508 \mathrm{bp}$ as shown in Fig. (1). The result was closely correlated with the findings of the researchers (15). Who found $60 \%$ of $A$. baumannii isolates possessed the fim $H$ gene with molecular weight of was $508 \mathrm{bp}$ and the results were agreed with researchers Momtaz et al. (2). Who found that 90 isolates (47.38\%) of A. baumannii had this gene that isolate from hospital infection.

Table (3): percentage of virulence genes (fim $\mathrm{H}$ ) possessed by A. baumannii in different type of sampling

\begin{tabular}{cc}
\hline Source & Virulence genes fimH $(\%)$ \\
\hline Bacteremia & $(17.5) 7$ \\
\hline Respiratory tract Infection & $(5) 2$ \\
\hline Burns & $(7.5) 3$ \\
\hline Wounds & $(2.5) 1$ \\
\hline Stool & $(17.5) 7$ \\
\hline UTI & 0 \\
\hline Total & $(50) 20$ \\
\hline
\end{tabular}

*(fimH= fimbriae)
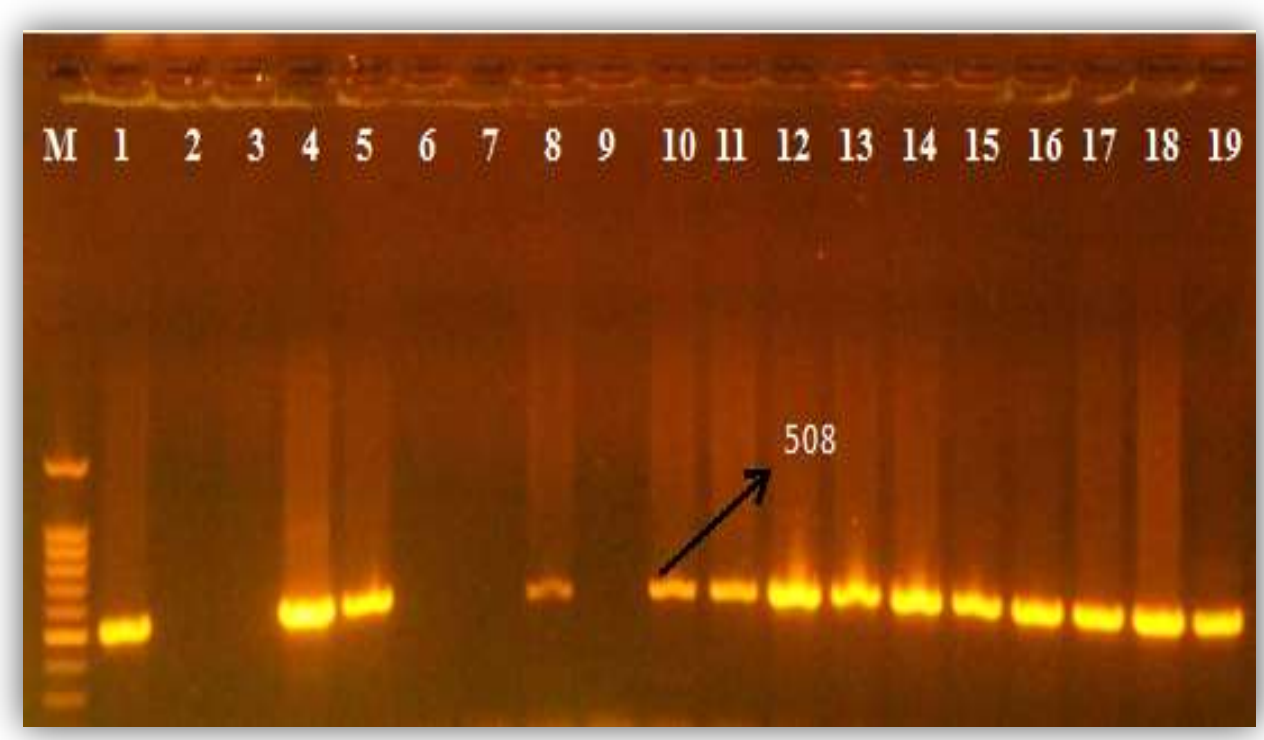

Figure (1- A): Agarose gel electrophoresis of the PCR product of the fim $H$ gene (508 bp) of $A$. baumannii isolates on $2 \%$ Agarose gel and 100 volts for 80 min. Line M: DNA marker (100-1500bp Ladder, Promega, USA); Lanes (1, 4, 5, 8, 10, 11, 12, 13, 14, 15, 16, 17, 18, 19) A. baumannii PCR positive isolate 


\section{M $20 \quad 2122 \quad 23 \quad 242526 \quad 2728 \quad 2930313233 \quad 34 \quad 35 \quad 36 \quad 3738$}

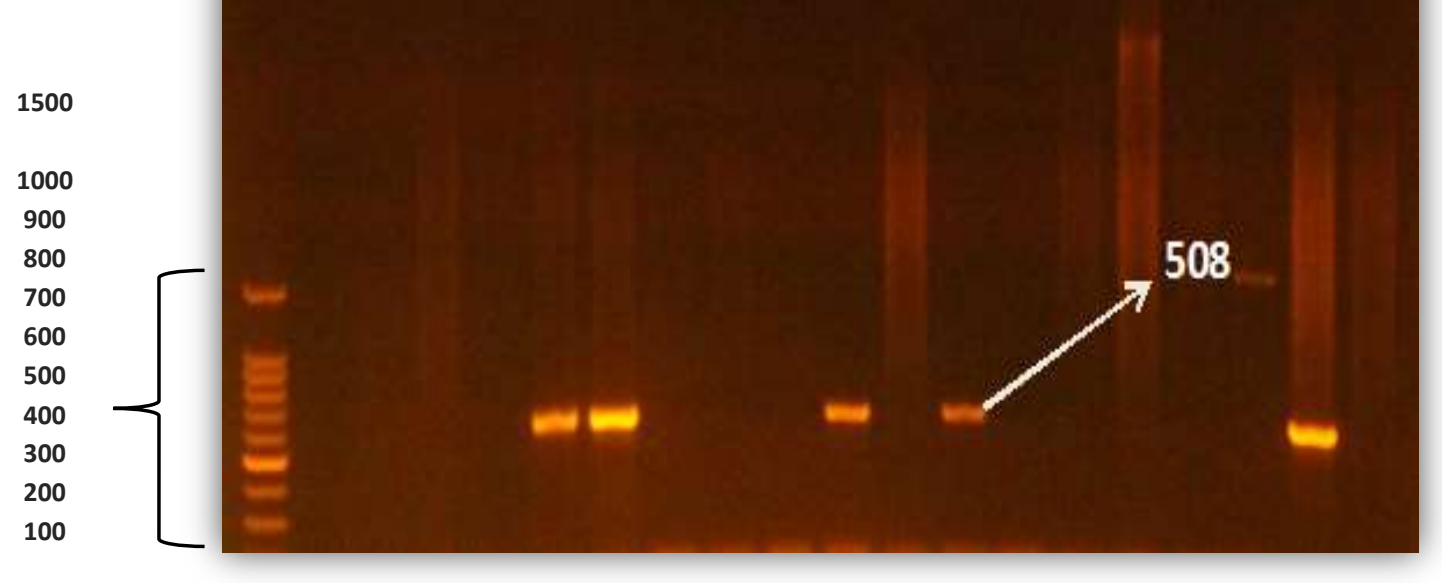

Figure (1-B): Agarose gel electrophoresis of the PCR product of the fim $H$ gene (508 bp) of $A$. baumannii isolates on $2 \%$ Agarose gel and 100 volts for 80 min. Line M: DNA marker (100-1500bp Ladder, Promega, USA); Lanes $(24,25,29,31,37)$ A. baumannii PCR positive isolate

Analyzed the DNA sequence of the fim $H$ gene. The results showed that there were mutations in the fim $H$ gene of isolation A23 and A23 from respiratory tract infection from A. baumannii. The substitution of the thymine with the adenine was obtained at 88 Subject- 4549236. Thymine were substituted with cytosine at 205 (4549353) and 237 (459384) respectively, as shown in Table (4) and Figure (2). When analyzing the results of the amino acid translation of the fim $H$ gene with the original amino acid found that this mutation did not affect the amino acid change as described in the Figure (2).The results of the mutations analysis showed that all mutations were silent mutations which produced the same amino acid and did not affect protein translation. Lamhef and Schlotterer s Studies showed that the types of insertions and Deletion mutations result from adding or removing one or more nucleotides to a DNA tape that may not affect In the translation of protein function (16).

Table (4): Changes in nitrogen bases and their effect on the translation of fim $H$ gene for the isolates

A20 and A23 of A. baumannii

\begin{tabular}{cccccc}
\hline Nitrogenous base & $\begin{array}{c}\text { Changes in } \\
\text { nitrogen bases }\end{array}$ & Position & Subject & Amino acid & $\begin{array}{c}\text { Changes in } \\
\text { amino acid }\end{array}$ \\
\hline Thymine & Adenine & $\mathbf{8 8}$ & 4549236 & Valine & Valine \\
Thymine & Cytosine & 205 & 4549353 & Serine & Serine \\
Thymine & Cytosine & 237 & 4549384 & Threonine & Threonine \\
\hline
\end{tabular}

The fim $H$ gene has been registered at National Center for Biotechnology Information

(NCBI) at the following link:- https://www.ncbi.nlm.nih.gov/nuccore/LC338015 


\section{Conclusions}

The results of the investigation of fimH in Acinetobacter baumannii showed that A. baumannii had a fimH gene $47.5 \%$ of isolates were studied. Sequencing analysis of fimH gene showed mutant mutations that did not affect protein translation and other mutations that led to a change in amino acid order and protein translation.

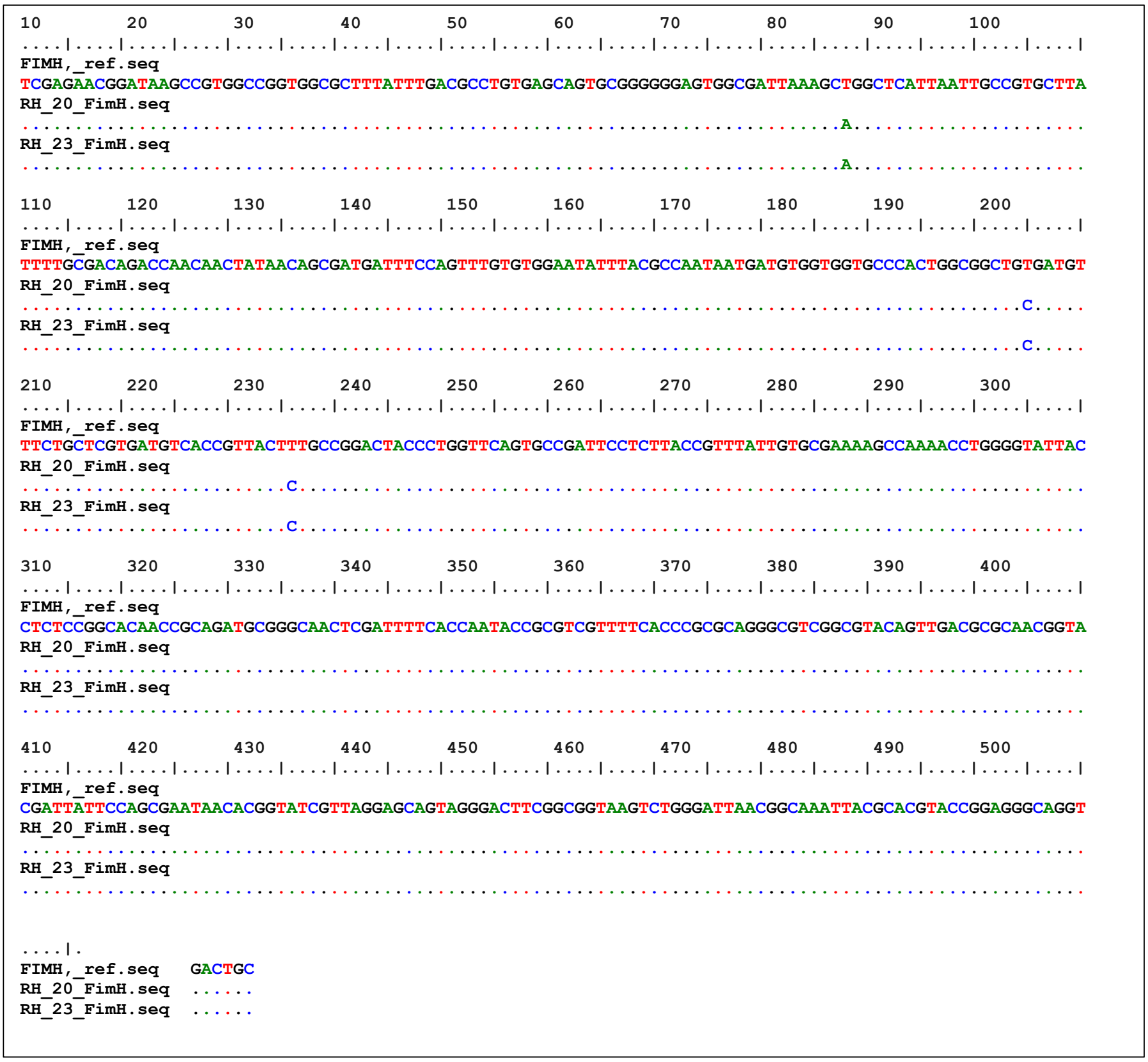

Figure (2): Analysis of multiple gene sequences of fim $\mathrm{H}$ reference with two changes to A20 and A23 isolates of A. baumannii using the BioEdit Sequence Alignment Editor Software 
References

1. Lambiase A, Piazza O, Rossano F, Pezzo MD, Tufano R, Catania MR. Persistence carbapenem-resistant Acinetobacter baumannii strains in an Italian intensive care unit during a forty-six month study period. New Microbiological.(2012); 35: 199-206.

2. Momtaz H, Seifati S, Tavakol M. Determining the Prevalence and Detection of the Most Prevalent Virulence Genes in Acinetobacter baumannii Isolated from Hospital Infections. Int.J. Med. Lab.(2015); 2(2): 87-97.

3. Visca P1, Seifert H, Towner KJ. Acinetobacter infection--an emerging threat to human health. IUBMB Life.(2011);63(12):1048-54.

4. Wisplinghoff H, Seifert H. Epidemiology and clinical features of Acinetobacter baumannii infections in humans. Berl Munch Tierarztl Wochenschr.(2014);127 (11-12):447-57.

5. Magnet $S$. Courvalin $P$.Lambert $T$. Resistance-nodulation-cell division-type efflux pump involved in aminoglycoside resistance in Acinetobacter baumannii strain BM4454. Antimicrob. Agent Chemothe .(2001);45:3375 - 3380 .

6. Sevillano E, Moreno, Funes F. Espinoza, M. Bustamante, Z.Gallego, L. First Detection of the bla oxa gene in multidrug resistant A. baumannii clinical isolated from Bolivia. J. inf. Deses count.(2016).

7. Dijkshoorn L, Brouwer CPJ, Boggards SJ, Nemec A, Broek PJV, Nibbering PH. The Synthetic N-Terminal Peptide of Human Lactoferrin, hLF (1-11), Is Highly Effective against Experimental Infection Caused by Multidrug-Resistant Acinetobacter baumannii . Antimicrob. Agent Chemothe.(2004); 48 (12) : 4919-492.

8. Abdulla AA, AL Thahab AA, Abed TA, Mahdi RK, Fadhil S. Screening of virulence factors in Acintobacter baumannii isolated from clinical samples. Int. J. Curr. Res and Acad. Rev.(2015); 3 (6): 128-134.

9. Blumer C, Kleefeld A, Lehnen D, Heintz M, Dobrindt U, Nagy G, Michaelis K, Emödy L, Polen T, Rachel R, Wendisch VF, Unden G. Regulation of type 1 fimbriae synthesis and biofilm formation by the transcriptional regulator LrhA of Escherichia coli. Microbiology.(2005); 151: 3287-3298.

10. Schwan WR. Regulation of fim genes in uropathogenic Escherichia coli. World of J. Clinical Infectious Diseases.(2011); 1: 17-25.

11. Baron EJ, Finegold SM, Peterson ILR. Bailey and Scott‘s Diagnostic Microbiology. 9th ed. Mosby Company. Missouri.(2007).

12. Johnson JR, Stell AL. Extended virulence genotypes of Escherichia coli strains from patients with urosepsis in relation to phylogenic and host compromise. J. Infect. Dis. (2000); 181: 261-272.

13. Sambrook J, Rusell DW. Molecular cloning a laboratory manual. Cold spring Harbor, NY: cold spring Harbor Laboratory press.(2001).

14. Sundar SK, Kumari-Pushpa Rani TP, Vijayalakshmi B, Murugan M. Isolation and 16S rRNA Sequencing of Clinical Isolates of Acinetobacter baumanii. Int. J. .Curr. Microbial and App. Sci.(2014); 3 (5): 855-858.

15. Farahani A, Mohajeri P. Molecular epidemiology of MBL Producing Acinetobacter baumannii in the west of Iran. J. of Nosocomial Infection.(2014); 1(1):18-22.

16. Lamhof M, Schlotterer C. Fitness effects of advantageous mutation in evolving Escherichia coli populations. Proceedings of the National Academy of Sciences of the United States of America. (2001); 98 (3): 1112-1128. 